\title{
DETECTION OF LAND USE CHANGES IN NORTHEASTERN IRAN BY LANDSAT SATELLITE DATA
}

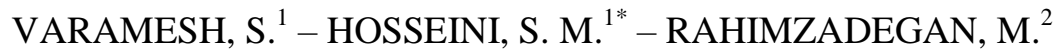 \\ ${ }^{I}$ Department of Forestry, Faculty of Natural Resources, Tarbiat Modares University \\ 64314 Noor, Mazandaran, Iran \\ ${ }^{2}$ Department of Water Resources, K. N. Toosi University of Technology, Tehran, Iran \\ *Corresponding author \\ e-mail:hosseini@modares.ac.ir \\ (Received $18^{\text {th }}$ Oct 2016; accepted $15^{\text {th }}$ Apr 2017)
}

\begin{abstract}
Land use is a dynamic process referring to human activities and various uses carried out over land. Population growth and elevated socio-economic necessities result in pressure on land use. Land use changes have been investigated in Golestan province located in northeastern Iran during 2000 - 2013 at a $30 \mathrm{~m}$ spatial resolution using Landsat ETM+ images. Support Vector Machines (SVMs) and Artificial Neural Networks (ANNs) algorithms were applied to classify land use changes. Land use reference data were used to classify and assess the accuracy of land use classification. Overall accuracy and kappa coefficients were calculated for the maps prepared by SVMs (93.74\% and 0.92, respectively) and ANNs approaches (93.08\% and 0.91 , respectively). In addition, accuracy over $85 \%$ is considered satisfactory for land use mapping and planning purposes. The SVM technique also was employed to prepare land use map of year 2000. The areas of each land use type were compared for land use maps of 2000 and 2013. The results obtained from the present study showed that the main land use changes in Golestan province was the conversion of forest and rangeland to agricultural and residential land uses.
\end{abstract}

Keywords: change detection; landsat images; land use classification; SVM; ANN

\section{Introduction}

Quantifying global and regional changes using earth observation data is an essential need given the changing status of global climate, biodiversity, food and other critical environmental and ecosystem services (Hansen et al., 2014).

Land use is a dynamic process that refers to human activities and various uses carried out over land, including agricultural land, built up land, recreation area, wildlife management area etc. (Reis, 2008). The population growth and increasing socioeconomic necessities will result in pressure on land use. This pressure can lead to uncontrolled changes in land use (Seto et al., 2002). However, these lands are being affected by destructive human activities (e.g. residential development, agriculture etc.) and socioeconomic factors (e.g. migration, population growth etc.) (Geri et al., 2010), leading to illegal resource use (Kuemmerle et al., 2009), and expanse bare land (Hostert et al., 2011; Pongratz et al., 2011).

Of the most dramatic socio-economic shocks in terms of area affected are desertification and population growth, which are recent pressures on land use of Golestan province in Iran. This process strongly influences forests, rangelands and agricultural land uses almost in all successions and this triggers drastic land-use changes. In Golestan province, forest harvesting has been elevated considerably with increasing illegal logging rates almost in all areas. In terms of agriculture, the dominant trend of land-use change is related to cropland and farmland in the central areas. 
Reforestation on bare land might have increased the whole forest area, but where and how much abandonment and reforestation happened remains unclear.

Up-to-date land use maps are helpful to scientists, land use planners, managers and policy makers. Satellite images and remote sensing technique have been widely used as a basis for land use mapping and improving our understanding of land use changes. Remote sensing technique is a powerful tool for spatial data acquisition to maintain the sustainable management of natural resources and economical perspective (Cetin, 2009). In this study, the proposed approaches were applied to prepare land use map and identify the land use change for a 13-year period in Golestan province that is characterized by rapid development and consequently land use changes. The main objective of this research is to record recent land use changes and highlight spatial conversion tendencies of the different land types with the use of remote sensing imagery and GIS. For this purpose, two Landsat ETM+ images were used and their characteristics were classified into six classes. For better classification, some vegetation and soil indices and band combinations along with a series of different classifiers were recruited in order to achieve high accuracy and extract authentic conclusions about the land-use changes in the study area.

\section{Material and methods}

\section{Study area}

The study area is located in northeastern Iran (Figure 1), between latitudes $36^{\circ} 30^{\prime}$ to $38^{\circ} 10^{\prime} \mathrm{N}$ and the longitudes $53^{\circ} 50^{\prime}$ to $56^{\circ} 20^{\prime} \mathrm{E}$ and covers an area of approximately $21400 \mathrm{~km}^{2}$. Altitude varies from about -40 to $3800 \mathrm{~m}$ above sea level. The climate is temperate with the annual average temperature of $16.88{ }^{\circ} \mathrm{C}$ and mean annual precipitation of $454 \mathrm{~mm}$.

The Golestan province is a major agricultural center, but includes substantive forest cover, residential areas, bare lands, rangelands and aquatic ecosystems of all sizes and densities. Our study site has been strongly influenced by socioeconomic changes. These characteristics make this province a suitable case study for comparative assessment of land use changes. In addition, the reasons for choosing this province are its environmental sensitivity and increasing tourist activity.

\section{Data}

The available data are four image scenes coming from the Enhanced Thematic Mapper plus sensor on board of Landsat 7 satellite and Enhanced Thematic Mapper plus sensor on board of Landsat 8 satellite (ETM+). The images were taken on July 16, 2000 and July 22, 2013 from the United States Geological Survey (USGS) Earth Resources Observation and Science Data (EROS) Center (http://eros.usgs.gov/). Finally, 240 training samples were collected from study area through Land Surveying GPS and Google Earth (Chen et al., 2011; Brandt et al., 2013). Training samples were collected evenly over the area with different slopes and altitudes. Figure 2 shows training samples in the study area including agriculture, desert, forest, rangeland, residential land uses and water body. Approximately $2 / 3$ of data were used for classification and the rest for accuracy assessment. The number of training samples is dependent on area of each land use type and difference of spectral characteristic. 

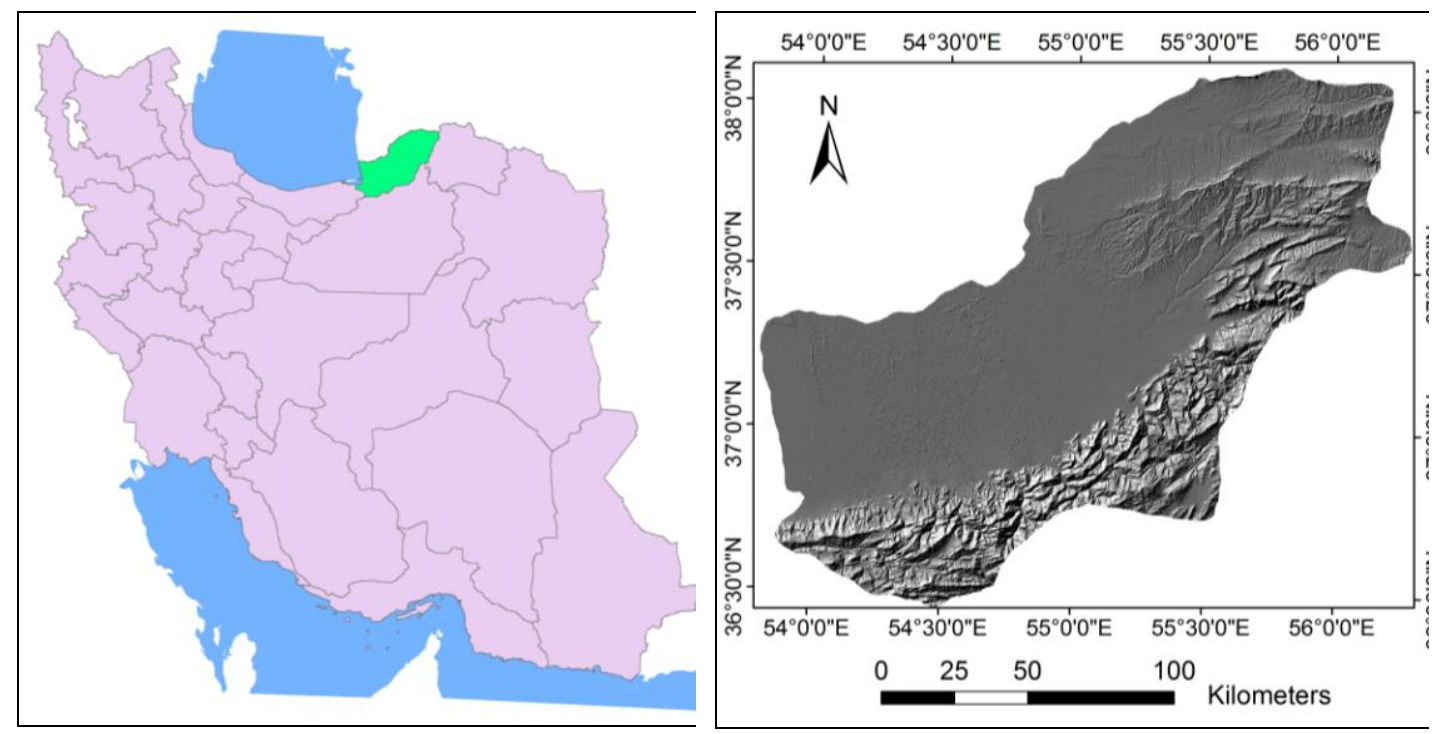

Figure 1. Location of Golestan province in northeastern Iran

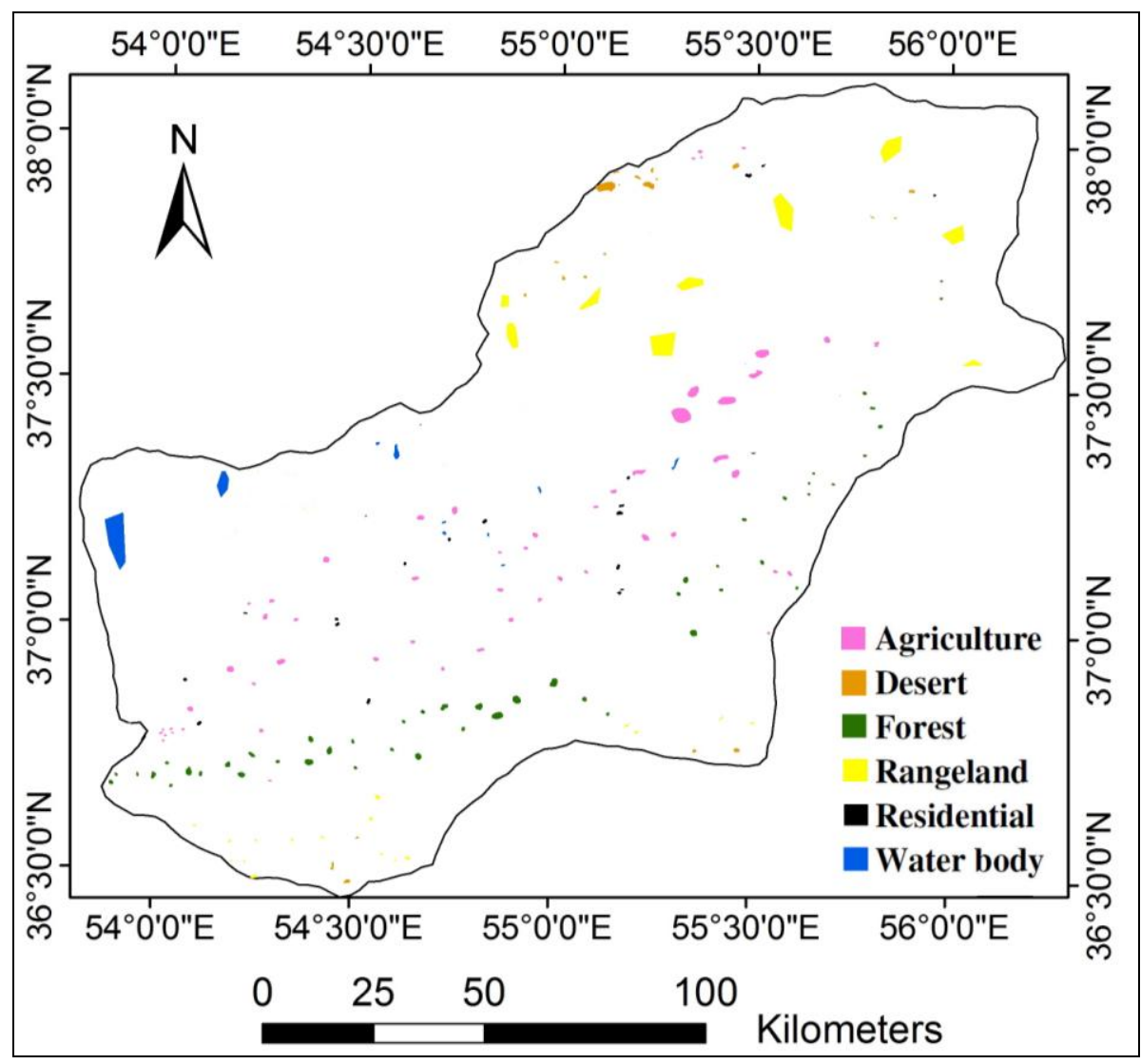

Figure 2. Training samples of Golestan province in northeastern Iran 


\section{Pre-processing of satellite images}

At the first step, DNs were converted into At-Satellite Radiance using following equation (Mausel et al., 2002).

$$
R=\{(R \max -R \min ) \mid(D N \max -D N \min )\} \times(\mathrm{DN}-\mathrm{DNmin})+R \min
$$

Where: $\mathrm{R}$ (units: $\mathrm{W}^{*} \mathrm{~m}^{-2} * \mathrm{sr}^{-1} * \mu \mathrm{m}^{-1}$ ) is the radiance at the top of atmosphere; Rmax, Rmin are band specific spectral radiances (Markham and Barker, 1987) and DNmax, DNmin are quantized calibrated digital numbers that are found in the metadata file on each of the image scenes.

Then following equation was applied to convert of At-Sensor Radiance to surface reflectance (Song et al., 2001):

$$
\rho=\pi \times \frac{(\text { Rsat }-R p)}{T v} \times\{(\text { Eo } \times \operatorname{Cos} \theta \times T z)+\text { Edown }\}
$$

Where: $\rho$ is the surface reflectance; $\mathrm{Rp}$ is the path radiance in $\mathrm{W} * \mathrm{~m}^{-2} * \mathrm{sr}^{-1} * \mathrm{~mm}^{-1}$; $\mathrm{TV}$ is the atmospheric transmittance from the land (or atmospheric) surface toward to the satellite sensor; $\mathrm{Tz}$ is the atmospheric transmittance in the illumination direction $\mathrm{W}^{*} \mathrm{~m}^{-}$ ${ }^{2} * \mathrm{sr}^{-1} * \mathrm{~mm}^{-1}$; Edown is the down welling diffuse irradiance in $\mathrm{W}^{*} \mathrm{~m}^{-2} * \mathrm{sr}^{-1} * \mathrm{~mm}^{-1}$; Eo is the exoatmospheric solar irradiance; $\theta$ is the solar zenith angle (Kolios and Stylios, 2013).

\section{Calculation of indices}

There are numerous indices to identify categories of vegetation and discriminate land types using satellite imagery (Lawrence and Ripple, 1998; Payero et al., 2004; Solaimani et al., 2011).

In this study, NDVI (normalized difference vegetation index) and BI (Brightness Index) were used that are focusing on the vegetation and soil type according following equations:

$$
\begin{gathered}
\text { NDVI }=\frac{(\text { Pnir }- \text { P red })}{(\text { Pnir }+ \text { Pred })} \\
B I=\left\{(\text { Pred })^{2}+(\text { Pgreen })^{2}+(\text { Pred })^{2}\right\}^{1 / 2} /(3)^{1 / 2}
\end{gathered}
$$

\section{Image classification}

The bands of Landsat images and indices were stacked and classification procedure was done on stacked file.

Determination of the land use classes is the first step of classification procedure that represents sufficiently every discrete land surface type of the study area. A visual examination and knowledge of expert helped us out to select the representative classes 
depicted at the satellite images. Additionally, the complexity of the surface characteristics and the $30 \mathrm{~m}$ spatial resolution of Landsat images led us to choose six well-discriminated land use types.

In this study, ENVI software has been used to perform separability tests (ENVI User's Guide, 2009) on sample pixels using indices including NDVI and BI.

After collecting training samples for each class, the images were classified. Then two classifiers including Support Vector Machine (SVM) and Artificial Neural Network (ANN) were used to prepare land use map.

ANN is a nonparametric algorithm that has no any assumptions on data distribution (Dixon and Candade, 2008). ANN is able to implement non-linear classification boundaries (Kavzoglu and Mather, 2003). SVM is an advanced classification algorithm widely used for land use classification (Huang et al., 2002; Mountrakis et al., 2011) aiming to find optimal planes for separating target classes with minimum misclassification. Likewise, some studies showed that SVM performs better than other algorithms, especially when small number of training data is available (Gualtieri and Cromp, 1999; Halder et al., 2011).

\section{Accuracy assessment}

Almost one third of training samples were not used for classification and considered for accuracy assessment of land use maps. To this end, overall accuracy and kappa coefficient was calculated using confusion matrix (Brandt et al., 2013). The overall classification accuracy shows the percentage of cells correctly classified. The kappa coefficient is a measure of chance-corrected classification recommended by Rosenfield and Fitzpatrick-Lins (1986). This standard has been widely used for accuracy assessment (Lillesand and Kiefer, 2000; Foody, 2002; Bakr et al., 2010; Abd el-kawy et al., 2011; Schmitt-Harsh, 2013). The United States Geological Survey has approved the kappa coefficient of $85 \%$ as minimum requirement for land use classification with Landsat data (Anderson et al., 1976).

\section{Land use change detection}

Using overall accuracy and kappa coefficient, the best classifier was selected to prepare land use map of year 2000. The area of each land use type was calculated for the land use maps of 2000 and 2013.

\section{Results and discussion}

Land use maps were extracted using ANN and SVM, as shown in Figures 3 and 4. The overall accuracy was obtained $93.74 \%$ and $93.08 \%$ for land use maps prepared using SVM and ANN respectively. Also kappa coefficient was 0.92 and 0.91 for land use map of SVM and ANN. The results indicated that SVM is more accurate than in ANN, so SVM was selected to prepare land use map of year 2000 (Figure 5). 


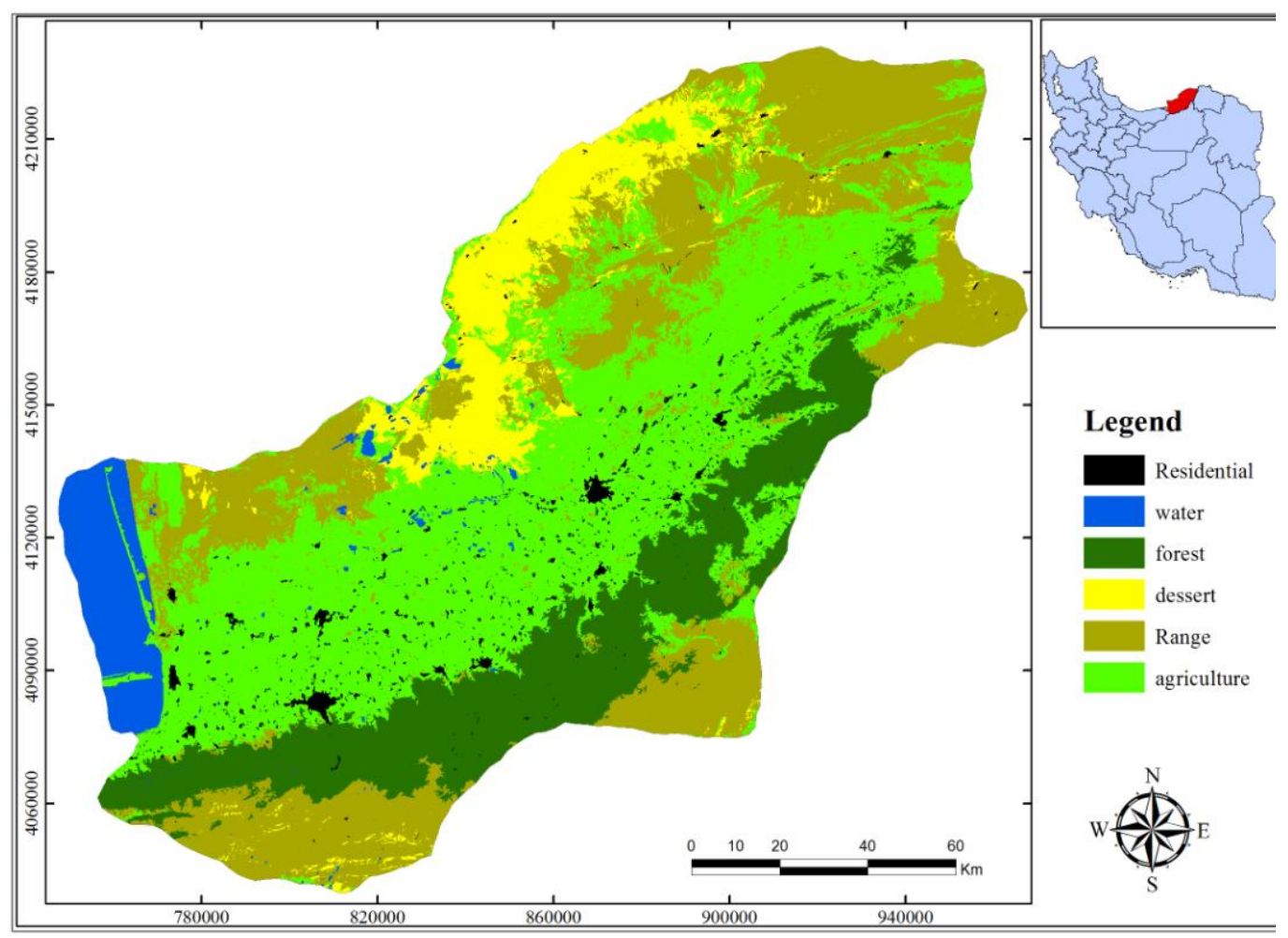

Figure 3. Land use map of 2013 prepared with SVM

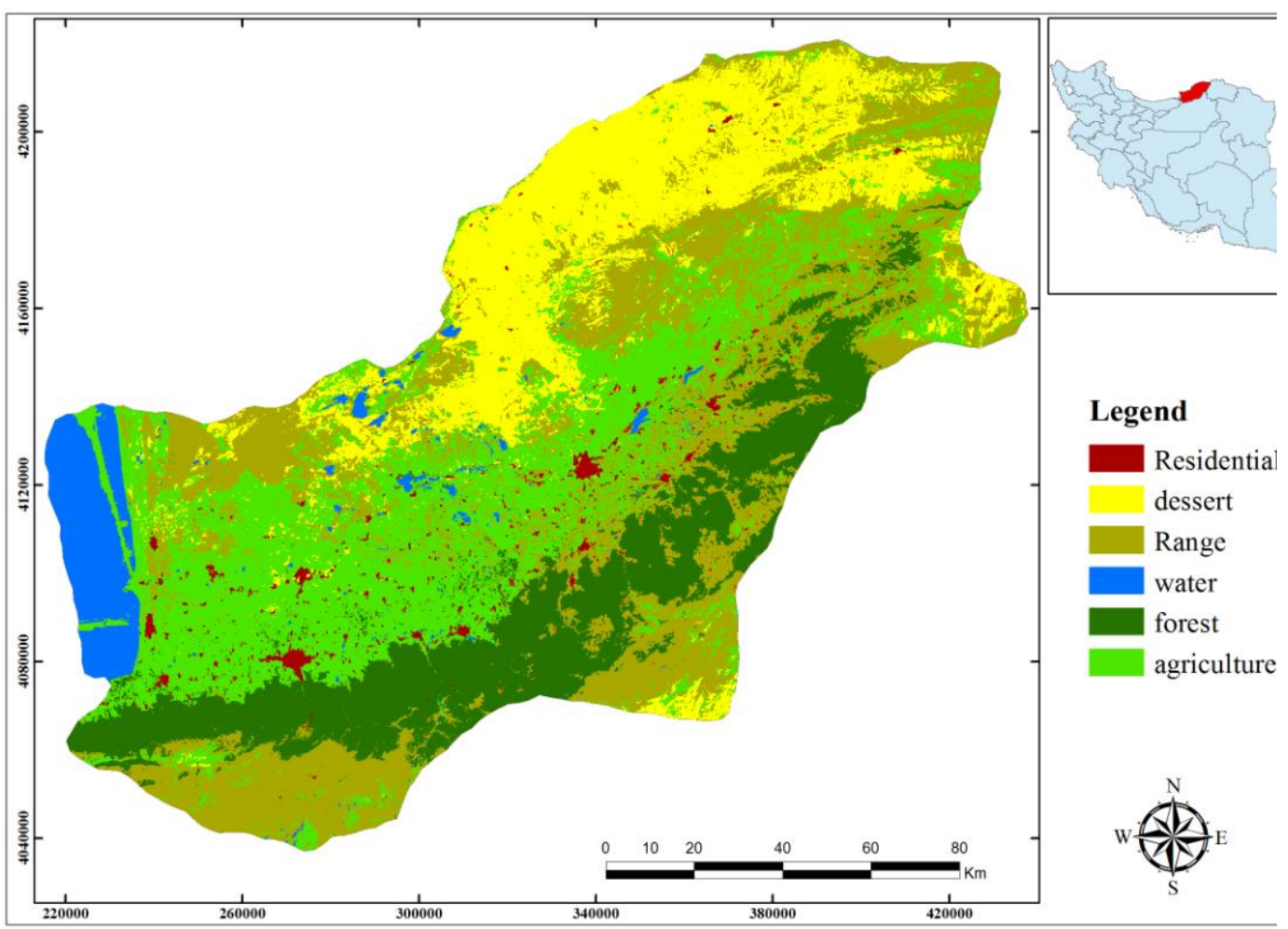

Figure 4.Land use map of 2013 prepared with ANN 


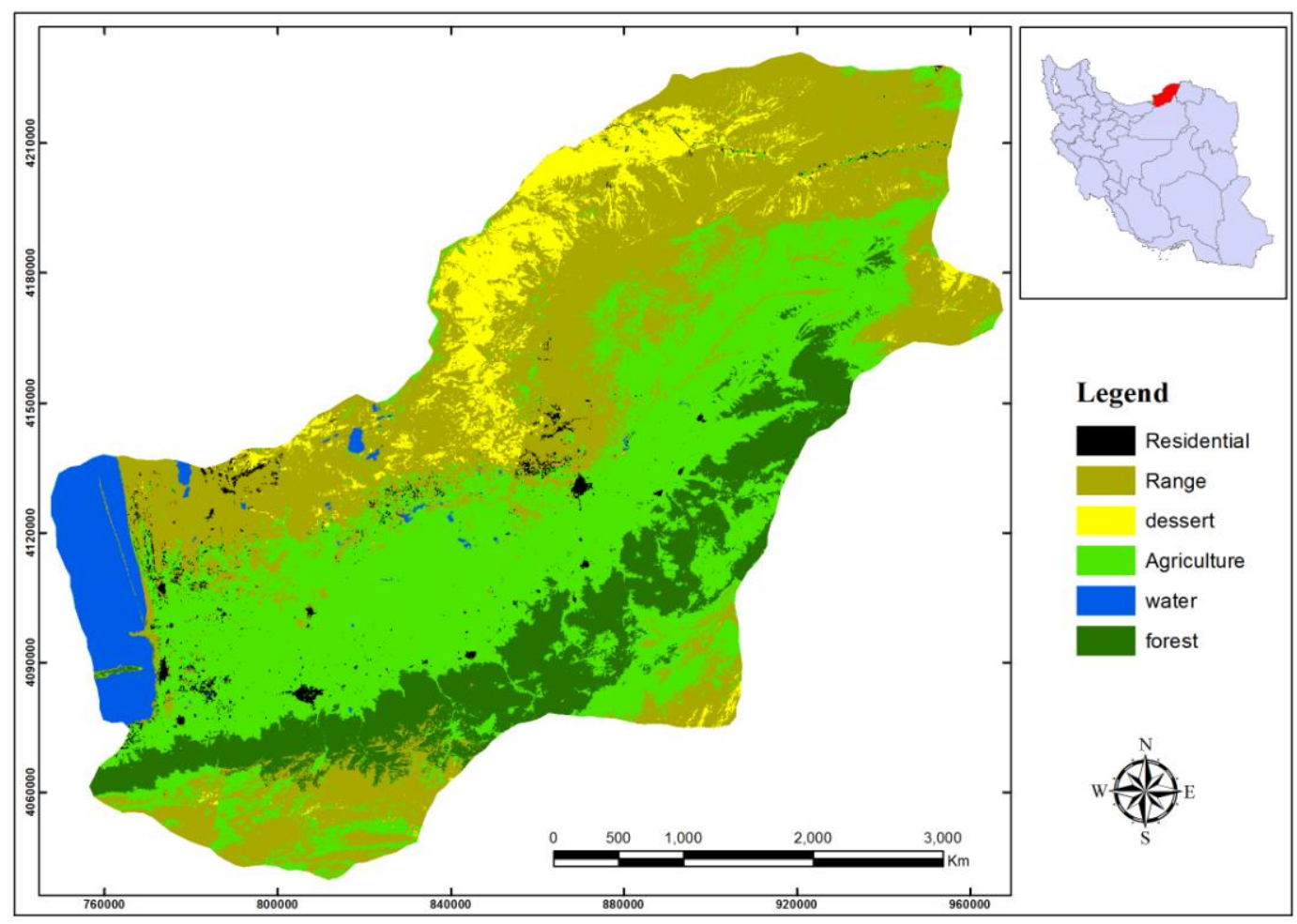

Figure 5. Land use map of 2000 prepared with SVM

The accuracy of land use map of 2000 was calculated as well. For this map, overall accuracy and kappa coefficient were estimated respectively $86.46 \%$ and 0.826 , which are acceptable outcomes.

The results of some previous researches also confirm accuracy of SVM method (Gualtieri and Cromp, 1999; Huang et al., 2002; Oommen et al., 2008; Otukei and Blaschke, 2010; Petropoulos et al., 2012). The kappa coefficient of the land use map of 2013 is more than 0.85 that has been consider as satisfactory for land use classification (Anderson et al., 1976). Moreover, the kappa coefficient of year 2000 was 0.826 closer to standard. In several reported land use mapping, the kappa coefficient is lower than standard. For example, Cingolani et al. (2004) showed kappa for maximum likelihood 0.74. In the study of Rozenstein and Karnieli (2010), kappa coefficient was 0.65 for ISODATA, and 0.53 for maximum likelihood 0.68 for synthetic method. Kappa coefficient in the study of Sun et al. (2011) was 0.82 for maximum likelihood model. Huang et al. (2010) obtained 0.76 for kappa coefficient.

The areas of each land use type were compared for land use maps of 2000 and 2013. The changes in land use from 2000 to 2013 are summarized in Table 1.

Our analyses revealed substantial and widespread land use changes in Golestan province in Iran, most importantly including residential, desert and farmland extension and deforestation due to illegal activities, mismanaged and unplanned policy. Earlier studies also confirm a widespread range of land use changes in Iran (Niknahad et al., 2011; Ajami et al., 2012). The expanse of farmland and residential areas in recent years was the most widespread land-use changes in our study area. Agricultural activities have increased in study area since 1990, and interestingly rangelands and forests are increasing to produce both food and bioenergy in Iran (Mirakhorlou et al., 2006). 
Our analyses also highlighted that the study area land-use changes have fundamentally restructured the region. The trend of these land use change likely affects landscape configuration; further researches are necessary to quantify these changes. Forest fragmentation is promoted by forest disturbances and simultaneously by the large-scale reforestation on bare land that provides the opportunity to increase forest cover and to establish novel connections between natural and planted species habitats.

Table 1. Change of land use types from 2000 to 2013

\begin{tabular}{c|c|c|c}
\hline Land use type & $\mathbf{2 0 0 0}$ & $\mathbf{2 0 1 3}$ & $\begin{array}{c}\text { Aand use change } \\
\left(\mathbf{K m}^{\mathbf{2}}\right)\end{array}$ \\
\hline Forest & 3220.05 & 2988.62 & -231.43 \\
Rangeland & 7935.95 & 6090.56 & -1845.39 \\
Agriculture & 7711.87 & 9241.85 & 1529.98 \\
Residential & 238.43 & 347.617 & 109.187 \\
Waterbody & 1021.73 & 944.38 & -77.35 \\
Desert & 1291.72 & 1806.72 & 515 \\
\hline
\end{tabular}

Numerous parts of Iran such as the study area are experiencing significant and contiguous land use changes mainly due to population growth and urbanization, forest fires and deforestation, abandoned the rangelands and meadows and the intensification of agriculture. These changes are very important especially for Golestan province whose local ecosystems, flora and fauna are mainly under tension because of increasing human activities. Tourist activity and emigration are additional factors affecting the biodiversity and sustainability of physical environment. Minetos and Polyzos (2010) expressed that the improvement of accessibility in an area accelerates land use changes and especially deforestation. Therefore, these activities in the study area need continuous monitoring and policies focused on developing the province regarding the protection of environment for a sustainable and well-being future of the area.

Studying land use changes in this province is a first step to design and implement a sustainable management policy for eliminating further degradation of local ecosystems.

Although our change detection approach demonstrated reliable maps, some uncertainties remain. For example, the future of barren land remains unclear, an appropriate management of barren land would lower the risk of exacerbating fires originating from these lands with unmanaged forest successions that may impact both biodiversity and ecosystem services (Navarro and Pereira, 2012).

The findings of the present study revealed that because of the specific characteristics of each study area, there are no image classifiers uniformly applicable to a great range of applications (Xie et al., 2008). For this reason, we tried to meet the needs of the study by taking into account the spatio-temporal accuracy of the initial use satellite imagery as well as the pre-processing steps of the image analysis (Kolios and Stylios, 2013). We also examined different band combinations and vegetation/soil indices to achieve a statistically accurate classification for our study area.

From an environmental point of view, the results of our classification provide useful information on land use changes in a study area. Although several factors motivated uncertainties exist in terms of accuracy of classification results (Schulz et al., 2010; Shao and $\mathrm{Wu}, 2008$ ), but the classification using satellite images is a very useful and powerful tool to identify land use change dynamics with satisfactory reliability. 


\section{Conclusion}

The rapid mismanagement and socio-economic changes can trigger a drastic episode of land-use change in Golestan province. Using a Landsat images, we found potent changes in logging regimes as well as widespread rangelands and forests conversion with extensive farmland and Riceland, which likely were triggered by the fundamental socio-economic and institutional transformations. Herein, we showed that forests, rangeland and water bodies whose areas have been decreased, but the areas of residential, desert and farmland have been increased during the period of 2000 to 2013. Even during the last turbulent years, this province has had adverse effects, highlighting the effect of destructive activities. In the future, the trend of land use change may pose both threats and opportunities. Threats include continued or increased illegal activities resulting in high habitat fragmentation, the spread of fires where forests are unmanaged, or recultivation of currently unused lands, whereas opportunities could rise where forest expansion on former barren lands increases habitat availability and connectivity. It is difficult to predict socio-economic shocks, a reason for wide range of possible outcomes in biodiversity scenarios. Finally, it should be noted that integration of remote sensing with matching statistics is a promising step to monitor the areas such as our study area within the larger landscape embedded in. According to our results, it is concluded that SVM and ANN can prepare correctly and satisfactory classification accuracy values, even for large size and complex terrain areas (regarding to their homogeneity), such as the study area, using data from visible different band combinations with vegetation and soil indices. Besides, the specific characteristics of a study area, the number of classes, the selection and the size of training samples, the pre-processing of the initial data, the used bands and indices for the corresponding dates play a significant role in the quality of final classification images. As a result, all these parameters should be used to extract satisfactory classification results.

\section{REFERENCES}

[1] Abd el-kawy, O. R., Ismail, H. A., Suliman, A. S. (2011): Land use and land cover change detection in the western Nile delta of Egypt using remote sensing data. - Applied Geography 31(2): 483-494.

[2] Ajami, M., Khormali, F., Ayoubi, Sh. (2012): Role of deforestation and land use change on soil erodibility of loess in eastern Golestan province. - Watershed Management Research (Pajouhesh \& Sazandegi) 94: 36-44.

[3] Anderson, J. R., Hardy, E. E., Roach, J. T., Witmer, R. E. (1976): A land use and land cover classification system for use with remote sensor data: Geological survey professional paper 964. - United States Government Printing Office, Washington D.C.

[4] Bakr, N., Weindorf, D. C., Bahnassy, M. H., Marei, S. M., El-badawi, M. M. (2010): Monitoring land cover changes in a newly reclaimed area of Egypt using multitemporal Landsat data. - Applied Geography 30(4): 592-605.

[5] Brandt, J. S., Haynes, M. A., Kuemmerle, T., Waller, D. M., Radeloff, V. C. (2013): Regime shift on the roof of the world: alpine meadows converting to shrublands in the southern Himalayas. - Biological Conservation 158: 116-127.

[6] Cetin, M. (2009): A satellite based assessment of the impact of urban expansion around a lagoon. - International Journal of Environmental Science and Technology 6(4):579-590.

[7] Chen, J., Zhu, X., Vogelmann, J. E., Gao, F., Jin, S. (2011): A simple and effective method for filling gaps in Landsat ETM? slc-off images. - Remote Sensing the Environment 115(4):1053-1064. 
[8] Cingolani, A. A., Renison, D., Zak, M. R., Cabido, M. R. (2004): Mapping vegetation in a heterogeneous mountain rangeland using Landsat data: an alternative method to define and classify land-cover units. - Remote Sensing of Environment 92(1): 84-97.

[9] Dixon, B., Candade, N. (2008): Multispectral landuse classification using neural networks and support vector machines: One or the other, or both? - International Journal of Remote Sensing 29(4): 1185-1206.

[10] ENVI User's Guide. (2009): ENVI on-line software user's manual. ITT Visual Information Solutions.

[11] Foody, G. M. (2002): Status of land cover classification accuracy assessment. - Remote Sensing the Environment 80(1): 185-201.

[12] Geri, F., Amici, V., Rocchini, D. (2010): Human activity impact on the heterogeneity of a Mediterranean landscape. - Applied Geography 30(3): 370-379.

[13] Gualtieri, J. A., Cromp, R. F. (1999): Support vector machines for hyperspectral remote sensing classification. Proceedings of SPIE. - The International Society for Optical Engineering 3584: 221-232.

[14] Halder, A., Ghosh, A., Ghosh, S. (2011): Supervised and unsupervised landuse map generation from remotely sensed images using ant based systems. - Applied Soft Computing Journal 11(8): 5770-5781.

[15] Hansen, M. C., Egorov, A., Potapov, P. V., Stehman, S. V., Tyukavina, A., Turubanova, S. A., Roy, D P., Goetz, S. J., Loveland, T. R., Ju, J., Kommareddy, A., Kovalskyy, V., Forsyth, C., Bents, T. (2014): Monitoring conterminous United States (CONUS) land cover change with Web-Enabled Landsat Data (WELD). - Remote Sensing of Environment 140: 466-484.

[16] Hostert, P., Kuemmerle, T., Prishchepov, A., Sieber, A., Lambin, E. F., Radeloff, V. C. (2011): Rapid land use change after socio-economic disturbances: The collapse of the Soviet Union versus Chernobyl. - Environmental Research Letters 6(4): 045201.

[17] Huang, C., Davis, L. S., Townshend, J. R. G. (2002): An assessment of support vector machines for land cover classification. - International Journal of Remote Sensing 23(4): 725-749.

[18] Huang, C., Goward, S. N., Masek, J. G., Thomas, N., Zhu, Z., Vogelmann, J. E. (2010): An automated approach for reconstructing recent forest disturbance history using dense Landsat time series stacks. - Remote Sensing of the Environment 114(1): 183-198.

[19] Kavzoglu, T., Mather, P. M. (2003): The use of backpropagating artificial neural networks in 267 land cover classification. - International Journal of Remote Sensing 24(23): 4907-4938.

[20] Kolios, S., Stylios, C. D. (2013): Identification of land cover/land use changes in the greater area of the Preveza peninsula in Greece using Landsat satellite data. - Applied Geography 40:150-160.

[21] Kuemmerle, T., Chaskovskyy, O., Knorn, J., Radeloff, V. C., Kruhlov, I., Keeton, W. S. (2009): Forest cover change and illegal logging in the Ukrainian Carpathians in the transition period from 1988 to 2007. - Remote Sensing of Environment 113(6): 11941207.

[22] Lawrence, L. R., Ripple, J. W. (1998): Comparisons among vegetation indices and bandwise regression in a highly disturbed, heterogeneous landscape: Mount St. Helens, Washington. - Remote Sensing of Environment 64(1): 91-102.

[23] Lillesand, T. M., Kiefer, R. W. (2000): Remote sensing and image interpretation. - John Wiley and sons, New York.

[24] Markham, B. L., Barker, J. L. (1987): Thematic Mapper bandpass solar exoatmospheric irradiances. - International Journal of Remote Sensing 8(3): 517-523.

[25] Mausel, D., Brondizio, E., Moran, E. (2002): Assessment of atmospheric correction methods for Landsat TM data applicable to Amazon basin LBA research. - International Journal of Remote Sensing 23(13): 2651-2671. 
[26] Minetos, D., Polyzos, S. (2010): Deforestation processes in Greece: a spatial analysis by using an ordinal regression model. - Forest Policy and Economics 12(6): 457-472.

[27] Mirakhorlou, K., Amin Amlashi, M., Karimi Doust, A., Jafari, B., Noki, Y., Amani, M. (2006): Investigation on boundary changes of northern forests of Iran using remotely sensed data. - Research Institute of Forest and Rangeland, Karaj (Iran). Report No 28021. (In Persian).

[28] Mountrakis, G., Im, J., Ogole, C. (2011): Support vector machines in remote sensing: A review. - ISPRS Journal of Photogrammetry and Remote Sensing 66(3): 247-259.

[29] Navarro, L., Pereira, H. (2012): Rewilding abandoned landscapes in Europe. Ecosystems 15(6): 900-912.

[30] Niknahad, G. H., Maramaei, M. (2011): Effects of land use changes on soil properties (Case Study: the Kechik catchment). - Journal of Soil Management and Sustainable Production 1(2): 81-96.

[31] Oommen, T., Misra, D., Twarakavi, N. K. C., Prakash, A., Sahoo, B., Bandopadhyay, S. (2008): An objective analysis of support vector machine based classification for remote sensing.- Mathematical Geosciences 40(4): 409-424.

[32] Otukei, J. R., Blaschke, T. (2010): Land cover change assessment using decision trees, support vector machines and maximum likelihood classification algorithms. International Journal of Applied Earth Observation and Geoinformation 12(1): 27-31.

[33] Payero, O. J., Neale, M. U. C., Wright, L. J. (2004): Comparison of eleven vegetation indices for estimating plant height of alfalfa and grass. - Applied Engineering in Agriculture 20(3): 285-393.

[34] Petropoulos, P., Kontoes, C., Keramitsoglou, I. (2012): Land cover mapping with emphasis to burnt area delineation using co-orbital ali and Landsat TM imagery. International Journal of Applied Earth Observation and Geoinformation 18: 344-355.

[35] Pongratz, J., Caldeira, K., Reick, C. H., Claussen, M. (2011): Coupled climate-carbon simulations indicate minor global effects of wars and epidemics on atmospheric $\mathrm{CO}_{2}$ between ad 800 and 1850. - The Holocene 21: 843-851.

[36] Reis, S. (2008): Analyzing Land Use/Land Cover Changes Using Remote Sensing and GIS in Rize, North-East Turkey. - Sensors 8: 6188-6202.

[37] Rosenfield, G., Fitzpatrick-Lins, K. (1986): A coefficient of agreement as a measure of thematic classification accuracy. - Photogrammetric Engineering and Remote Sensing 52(2): 223-227.

[38] Rozenstein, O., Karnieli, A. (2010): Comparison of methods for land-use classification incorporating remote sensing and GIS inputs. - Applied Geography 31(2): 533-544.

[39] Schmitt-Harsh, M. (2013): Landscape change in Guatemala: driving forces of forest and coffee agroforest expansion and contraction from 1990 to 2010. - Applied Geography 40: 40-50.

[40] Schulz, J. J., Cayuela, L., Echeverria, C., Salas, J. (2010): Monitoring land cover change of the dryland forest landscape of Central Chile (1975-2008). - Applied Geography 30(3): 436-447.

[41] Seto, K. C., Woodcock, C. E., Song, C., Huang, X., Lu, J., Kaufmann, R. K. (2002): Monitoring land use change in the Pearl River Delta using Landsat TM. International. Journal of Remote Sensing 23(10): 1985-2004.

[42] Shao, G., Wu, J. (2008): On the accuracy of the landscape pattern analysis using remote sensing data. - Landscape Ecology 23(5): 505-511.

[43] Solaimani, K., Shokrian, F., Tamartash, R., Banihashemi, M. (2011): Landsat ETM based assessment of vegetation indices in highland environment. - Journal of Advances in Developmental Research 1: 5-13.

[44] Song, C., Woodcock, E. C., Seto, C. K., Lenney, P. M., Macomber, A. S. (2001): Classification and land change detection using Landsat TM data: when and how to correct atmospheric effects? - Remote Sensing of Environment 75: 230-244. 
[45] Sun, J., Yang, J., Zhang, C., Yun, W., Qu, J. (2011): Automatic remotely sensed image classification in a grid environment based on the maximum likelihood method. Mathematical and Computer Modelling 58(3-4): 573-581.

[46] Xie, Y., Sha, Z., Yu, M. (2008): Remote sensing imagery in vegetation mapping: a review. - Journal of Plant Ecology 1(1): 9-23. 